\title{
Extent of lymphadenectomy in radical cystectomy for bladder
}

\section{cancer}

\author{
M Hammad Ather*1, Sadaf Fatima ${ }^{1}$ and Orhun Sinanoglu ${ }^{2}$
}

Address: ${ }^{1}$ Department of Surgery, Aga Khan University Hospital, Karachi, Pakistan and ${ }^{2}$ Taksim Teaching Hospital Urology Clinic, Istanbul, Turkey Email: M Hammad Ather* - hammad.ather@aku.edu; Sadaf Fatima - dr_sadafatima@yahoo.co.uk; Orhun Sinanoglu - orhundr@hotmail.com

* Corresponding author

Published: 15 July 2005

World Journal of Surgical Oncology 2005, 3:43 doi:10.1 186/1477-7819-3-

43

This article is available from: http://www.wjso.com/content/3/l/43

(C) 2005 Ather et al; licensee BioMed Central Ltd.

This is an Open Access article distributed under the terms of the Creative Commons Attribution License (http://creativecommons.org/licenses/by/2.0), which permits unrestricted use, distribution, and reproduction in any medium, provided the original work is properly cited.
Received: 22 March 2005

Accepted: 15 July 2005

\begin{abstract}
Background: The benefit of pelvic lymphadenectomy in patients with cancer of the urinary bladder remains controversial. Though the inclusion of lymph node dissection in conjunction with radical cystectomy for patients with clinically negative nodes is well accepted, however, the extent of the nodal dissection remains contentious, particularly in patients with gross disease and $T_{1} G_{3}$ cancer. The extent of the primary bladder tumor, number of lymph nodes removed and the lymph node tumor burden are important prognostic variables in patients undergoing cystectomy. We analyzed the impact of the extent of lymphadenectomy during radical cystectomy on survival in the contemporary literature.
\end{abstract}

Methods: A Pubmed search was carried out for the literature published over the last 15 years using bladder cancer, radical cystectomy, survival, lymphadenectomy and complications as the key words. We have discussed the extent of lymphadenectomy on survival and its anatomical basis to determine the optimal number of lymph nodes to be removed and the concept of node density.

Results: Evidence from contemporary literature indicate significantly increased survival rates after cystectomy in patients with bladder cancer diagnosed with stages III or IV disease who have had relatively more lymph nodes examined, suggesting that even some patients with higher stage disease may benefit from extended pelvic lymphadenectomy at the time of cystectomy. Studies also indicate that more extensive lymphadenectomy significantly improved the prognosis of patients with bladder cancer, not only by providing prognostic information but perhaps it is also due to its inherent therapeutic value.

Conclusion: Extended lymph node dissection improves local control and survival. However, in the absence of controlled randomized trial this remains a dubitable issue.

\section{Background}

Bladder cancer is the second most common tumor of the urogenital tract with transitional cell carcinoma comprising of about $90 \%$ of all primary bladder malignancies [1]. Most of these tumors are superficial at initial presentation, limited to the mucosa, sub-mucosa or lamina propria. In superficial cancers, recurrence rates after initial treatment are $50-80 \%$ with progression to muscle invasive disease in $10-25 \%$ cases, whereas in muscle invasive disease there is $50 \%$ risk of loco-regional and distant metastasis. 
The transitional cell carcinomas (TCC) originates in the bladder mucosa, progressively invading the lamina propria and more sequentially involves muscularis propria, perivesical fat and contiguous pelvic structures with increasing incidence of lymph node involvement during progression [2,3].

Radical cystectomy is the corner stone of treatment for invasive bladder cancers in patients whose medical condition allows major surgical procedure $[1,4]$. Five-year life expectancy is $75 \%$ for $\mathrm{T}_{2}$ lesions, $40 \%$ for $\mathrm{T}_{3}$ and $25 \%$ for $\mathrm{T}_{4}$ lesions [5]. The outcome for bladder cancer patients have improved primarily because of advances in surgical technique and better peri-operative care. However $70 \%$ of the patients with node positive disease develop tumor recurrence if treated by cystectomy alone. Proper staging of disease and timely institution of adjuvant treatment could potentially make a difference.

In addition to the evaluation of the primary tumor in a cystectomy specimen, assessment of the regional lymph nodes is also important; not only to accurately stage the disease but also to identify the need for adjuvant treatment. Preoperative imaging studies CT scan or an MRI will miss microscopic nodal metastasis in up to $70 \%$ of the patients $[3,7,8]$ and this leaves histological evaluation as the only reliable tool in accurately staging the disease. The reported incidence of regional lymph node involvement following radical cystectomy is between $14 \%$ and $28 \%$ $[[5,6]$, and $[8]]$. These rates correlate with the stage of the tumor; the higher the stage, the higher is the incidence of the involved lymph nodes $[5,10,11]$. Lymph node involvement is associated with increased risk of local recurrence and disease progression with survival rates varying from $20 \%$ to $40 \%$ in patients with and without lymph nodes metastasis respectively $[5,10]$.

Pelvic lymphadenectomy is routinely performed as part of radical cystectomy for bladder cancers; however, there is lack of consensus on the intent (therapeutic or diagnostic) and limits of lymph node dissection. It is most often performed as a staging procedure. Some of the leading authorities believe that it has a potential therapeutic adjunct to radical cystectomy $[12,13]$.

The absolute limits or extent of lymphadenectomy for patients undergoing surgery with a curative intent has not been precisely defined. The recent guidelines for the treatment of muscle invasive bladder cancer by The European Association of Urology recommend limited pelvic node dissection. This consists of removing the tissue in the obturator fossa in patients undergoing surgery with a curative intent [14]. Whereas several authors have noted an improved 5-year survival with extensive pelvic lymph node dissection in patients with node positive bladder cancer $[2,3,15]$.

In the present review, we have attempted to analyze the current literature to see if there is convincing data to support the observation of some authors that extensive pelvic lymphadenectomy is associated with low pelvic and distant recurrence and survival.

\section{Extent of lymphadenectomy}

The minimum number of lymph nodes to be excised in order to obtain a therapeutic advantage remains an issue of controversy. Anatomical studies have defined the external and internal iliac lymph nodes and the obturator nodes as the site of primary lymphatic drainage of the bladder and the common iliac nodes as the site of secondary drainage, with the trigone and the posterior wall draining directly into the pre-sacral nodes [16].

The role and extent of lymphadenectomy in bladder cancer is not well-defined, in contrast, patients with gastric [17], breast [18], and colorectal [19] tumors the impact of lymphadenectomy has been well studied and there has been a consensus that complete lymph node dissection with removal of a minimum number of lymph nodes correlates with improved survival. Guidelines for the management of colon and rectal cancer indicate that at least 12-14 lymph nodes should be retrieved by the pathologist in patients with colorectal cancers [18] and at least 10 lymph nodes in patients with endometrial cancer [20], but this knowledge is lacking in cases of bladder cancers.

Several authors have postulated that the number of lymph nodes examined in cystectomy specimen can have an impact on the outcome of patients treated for primary bladder cancer $[9,13]$, whereas others have reported an improved survival with extensive nodal dissection $[15,22]$. Extensive lymphadenectomy increases the operating time and theoretically may increase the risk of hemorrhage and lymphocele formation, but studies have not shown a significant increase in morbidity with this procedure [22].

\section{Number of lymph nodes and impact on survival} Many factors can influence the outcome of patients with bladder cancer including the T-stage, the N-stage and the total number of lymph nodes retrieved. Skinner et al, [13] noted that important prognostic factors included age, gender and lymph nodes status but the number of involved nodes was the single most important prognostic variable. Lerner et Al, [2] observed that the 5-year survival probability in cases with 5 or fewer involved nodes was almost double than those with 6 or more involved nodes. Mills et $A l,[23]$ studied a group of 83 patients with nodes positive disease and reported similar results. The median number 
of retrieved nodes was 20/case. A significant survival difference was observed when patients with less than 5 involved nodes were compared with more than 5 involved lymph nodes ( $p=0.0027)$, however this significance was lost on multivariate analysis. Stein et al, [22] verified the impact of positive nodes on univariate as well as multivariate analysis with a cut off of 8 involved nodes [18]. Vieweg et al, [24] reported that in cases with organ confined disease, there was no survival difference between $\mathrm{N}_{0}$ and $\mathrm{N}_{1}$ groups but survival benefit consistently decreased from $\mathrm{N}_{1}$ to $\mathrm{N}_{3}$ disease. Konety et al, [25] studied 20,799 patients treated for primary bladder cancer and reported similar results. They concluded that regardless of the tumor stage, at least 14 lymph nodes should be excised in patients undergoing radical cystectomy. Herr $e t$ al, [26] studied the impact of lymph nodes in a group of 322 patients who underwent pelvic node dissection. They observed that in patients with $\mathrm{pN}_{0}$ status improved survival and local control was seen when the cut-off was 8 examined lymph nodes. However, in patients with pathologically involved nodes at least 9 lymph nodes should be removed.

\section{Anatomical extent of dissection}

Poulsen et al, [15] studied the influence of extent of nodal dissection on survival following radical cystectomy for bladder cancer. They compared 126 patients who underwent extensive pelvic dissection with proximal limits up to the bifurcation of aorta and 68 patients who underwent limited nodal dissection with proximal limits up to the common iliac vessels. The overall prevalence of nodal metastasis was slightly higher in patients with extended dissection as compared to ones with limited dissection. Extended dissection was associated with an improved 5year recurrence free survival for patients with tumor confined to the bladder ( $\mathrm{pT}_{3 \mathrm{a}}$ or less), but this was not true for tumors penetrating the bladder wall. This was a retrospective, non-randomized study and the anatomical mapping and the number of retrieved lymph nodes was not mentioned.

Herr et al, [21] introduced the term of lymph node density indicating the ratio between the numbers of nodes removed to the number of involved node. They found ratio based lymph node staging, which reflects the quality of lymph node dissection, was a significant prognostic variable for survival and local control in patients with lymph node positive bladder cancer after radical cystectomy. Later Stein et al, [22] reported their experience of 244 patients with involved lymph nodes treated for primary transitional cell carcinoma of bladder. They reported that the overall and recurrence free survival was significantly related to pathological subgroup of the primary bladder tumor, patients with organ-confined disease having a better survival as compared to those with extravesical tumors. Patients with a lymph node density of $20 \%$ or less had a better recurrence free survival when compared to those with more than $20 \%(\mathrm{p}<0.001)$, however this study confined to only the lymph node positive cases, the lymphadenectomy was done in en bloc fashion, and the exact anatomical location of the excised lymph nodes was not known. In an attempt to standardize the extent of dissection, Leissner et al [9] studied a group of 447 patients who underwent extended lymphadenectomy along with radical cystectomy for bladder cancer. The guidelines for lymphadenectomy were to remove obturator, internal, external and common iliac, pre-sacral and the lymph nodes on both sides of aortic bifurcation. The mean number of retrieved nodes was 16.7/patient. They observed that overall the tumor specific survival (P-value $<0.013$ ) and disease free survival was significant (P-value $<0.016$ ) when patients with $\geq 16$ excised lymph nodes were compared with those with $<15$ nodes removed, except for those with T-4 lesions. In presence of nodal metastasis patients only benefited by removal of at least five metastatic lymph nodes, thus supporting the therapeutic effect of extended lymphadenectomy.

The two possible reasons for better survival in patients with extended lymphadenectomy were explained by lymphadenectomy resulting in a more accurate staging so adjuvant therapy may be started earlier. The other possible explanation could be the increased likelihood of removing nodal tumor deposits. Conclusive evidence could not be derived from a retrospective studies and literature review.

Mills et al [23] reported their experience of 83 patients with node positive tumors who underwent pelvic lymphadenectomy. Anatomical mapping was done in the group of retrieved nodes. Survival correlated with the number of lymph nodes, adjuvant chemotherapy, capsular penetration and the site of metastatic nodes. On univariate analysis, survival was better when more than 5 positive lymph nodes was removed however this was not significant and only lymph node capsular penetration demonstrated a significant effect on survival. This was again a retrospective study but only the pelvic lymph nodes were dissected, therefore the nodal status of the proximal sites was unknown.

Vazina et al [27] reviewed their results of 176 patients who were treated with lymph node dissection up to the aortic bifurcation. The median number of lymph nodes excised was $25 /$ case. It was observed that the rate of nodal involvement gradually decreased from pelvic to aortic sites. They reported that these tumors did not exhibit skip metastasis as all. The patients except one who had involvement of lymph nodes at or above the aortic bifurcation or common iliac region also had positive lymph 
nodes in distal (pelvic and peri-vesical) areas. One patient who had involvement of the common iliac lymph nodes without involving the distal lymph nodes, had a primary lesion in the trigone explaining this to be presumably due to direct lymphatic drainage of the trigone area to the common iliac region. Bochner et al, [28] reported the survival status of 144 patients who were operated for primary bladder cancer, out of whom 56 underwent standard pelvic node dissection whereas 88 patients had extended dissection. Though, the yield of nodes was greater in extended dissection than in standard dissection, but both types had a similar percentage of patients with positive lymph nodes, however extended lymphadenectomy provided better prognostic information through a more accurate evaluation of the total number of lymph nodes excised or the number of involved lymph nodes. Extended lymphadenectomy identified $33 \%$ of patients with microscopic nodal metastasis involving the common iliac lymph nodes, explaining the therapeutic value of pelvic dissection. This is also supported by a European study of a group of 290 patients, who underwent extended radical lymphadenectomy along with radical cystectomy [29]. In this series, it was observed that $57 \%$ of patients with lymph node involvement at level I had nodal metastasis at level II and 31\% had level III nodes involved. Similarly, $35 \%$ patients with level II nodes involved were found to have level III nodal involvement, hence they concluded with a strong recommendation for extended lymphadenectomy in all patients undergoing radical cystectomy for bladder cancer with a curative intent. The three lymphadenectomy levels were defined by the authors as; level I, distal to the bifurcation of common iliac artery, level II distal aortic bifurcation up to level I and level III proximal to aortic bifurcation.

\section{Conclusion}

More than half the patients with locally advanced $\left(\mathrm{pT}_{3 \mathrm{a}}\right.$, $\mathrm{pT}_{3 \mathrm{~b}}, \mathrm{pT}_{4 \mathrm{a}}$ and/ or $\mathrm{pN}+$ ) treated by radical surgery will have disease progression in five years. Adequate staging affects the outcome of patients with bladder cancer. Such information is important not only for therapy and prognosis, but also in identifying individuals for adjuvant treatment. Evidence from contemporary studies indicates that more extensive lymphadenectomy significantly improved the prognosis of patients with bladder cancer. A growing body of evidence suggests that an extended lymph node dissection may provide not only improved prognostic information, but also a clinically significant therapeutic benefit for both lymph node-positive and -negative patients undergoing radical cystectomy. However, in the absence of randomized controlled trial, the scientific value of current evidence is at best level 2 .

\section{Competing interests}

The author(s) declare that they have no competing interests.

\section{Authors' contributions}

MHA. Conceived of the idea, helped in literature search and drafted part of the manuscript.

SF did the literature search, drafted most of the manuscript.

OS Wrote the initial draft and helped in literature search. All authors have read and approved of the final draft.

\section{References}

I. Stein JP, Lieskovsky G, Cote R, Groshen S, Feng AC, Boyd S, Skinner E, Bochner B, Thangathurai D, Mikhail M, Raghavan D, Skinner DG: Radical Cystectomy in the treatment of invasive bladder cancer: long term results in 1054 patients. J Clin Oncol 200I, 19:666-675.

2. Lerner SP, Skinner DG, Lieskovsky G, Boyd SD, Groshen SL, Ziogas A, Skinner E, Nichols P, Hopwood B: The rationale for en bloc pelvic lymph node dissection for bladder cancer patients with nodal metastases: Long term results. J Urol 1993, I49:758-765.

3. Ghoneim MA, el-Mekresh MM, el-Baz MA, el-Attar IA, Ashamallah A: Radical cystectomy for carcinoma of the bladder: critical evaluation of the results in I,026 cases. J Urol 1997 , 158:393-399.

4. Dalbagni G, Genega E, Hashibe M, Zhang ZF, Russo P, Herr H, Reuter $V$ : Cystectomy for bladder cancer: a contemporary series. $J$ Urol 2001, 165:1111-1116.

5. Frazier HA, Robertson JE, Dodge RK, Paulson DF: The value of pathological factors in predicting cancer-specific survival among patients treated with radical cystectomy for transitional cell carcinoma of bladder and prostate. Cancer 1993, 71:3993-400I.

6. Vieweg K, Gschwend JE, Herr HW, Fair WR: Pelvic lymph node dissection can be curative in patients with node positive bladder cancer. J Urol 1999, 16 1:449-454.

7. Herr HW, Bajorin D, Scher H, Cordon-Cardo C, Reuter VE: Can p53 help select patients with invasive bladder cancer for bladder preservation? J Urol 1999, 161:20-22.

8. Coloby PJ, Kakizoe T, Tobisu K, Sakamoto M: Urethral involvement in female bladder cancer patients: mapping of 47 consecutive cystourethrectomy specimens. J Urol 1994, 158: | 438-| 442

9. Ghoneim MA, Abol-Enein H: Lymphadenectomy with cystectomy: Is it necessary and what is its extent? Eur Urol 2004, 46:457-46I.

10. Leissner J, Hohenfellner R, Thuroff JW, Wolf HK: Lymphadenectomy in patients with transitional cell carcinoma of the urinary bladder; significance for staging and prognosis. BJU Int 2000, 85:8I7-823.

II. Lerner SP, Skinner E, Skinner DG: Radical cystectomy in regionally advanced bladder cancer. Urol Clin North Am 1992, 19:713-723.

12. Herr HW: Bladder Cancer: Pelvic lymphadenectomy revisited. J Surg Oncol 1998, 37:242-245.

13. Skinner DG: Management of invasive bladder cancer: a meticulous pelvic node dissection can make a difference. J Urol 1982, I 28:34-36.

14. Jakse G, Algaba F, Fossa S, Stenzl A, Sternberg C: Guidelines on bladder cancer, muscle-invasive and metastatic. European Association of Urology 2004 [http://www.uroweb.org/files/ uploaded files/guidelines/2289/ Bladder Cancer.pdf]. accessed on June 16, 2005

15. Poulsen AL, Horn T, Steven K: Radical cystectomy: extending the limits of pelvic node dissection improved survival for patients with bladder cancer confined to the bladder wall. Urol 1998, 160:2015-2019. 
16. Rouviere $\mathrm{H}$ : Anatomy of human lymphatic system Ann arbor, Michigan: Edward brothers; 1938:214.

17. Siewert JR, Bottcher K, Stein HJ, Roder JD: Relevant prognostic factors in gastric cancer: ten-year results of the German Cancer Study. Ann Surg 1998, 228:449-46I.

18. Mathiesen $O$, Carl J, Bonderup O, Panduro J: Axillary sampling and the risk of erroneous staging of breast cancer. An analysis of 960 consecutive patients. Acta Oncol 1990, 29:721-725.

19. Caplin S, Cerottini JP, Bosman FT, Constanda MT, Givel JC: For patients with Dukes' B (TNM Stage II) colorectal carcinoma, examination of six or fewer lymph nodes is related to poor prognosis. Cancer 1998, 83:666-672.

20. Sobin LH, Fleming ID: TNM Classification of Malignant Tumors, $5^{\text {th }}$ ed (1997). Union Internationale Contre le Cancer and American Joint Committee on Cancer. Cancer 1997 80:1803-1804

21. Herr HW: Superiority of ratio based lymph node staging for bladder cancer. J Urol 2003, 169:943-945.

22. Stein JP, Cai J, Groshen S, Skinner DG: Risk factors for patients with pelvic lymph node metastases following radical cystectomy with en bloc pelvic lymphadenectomy: the concept of lymph node density. J Urol 2003, I 70:35-4I.

23. Mills RD, Turner WH, Fleischmann A, Markwalder R, Thalmann GN, Studer UE: Pelvic lymph node metastases from bladder cancer: outcome in $\mathbf{8 3}$ patients after radical cystectomy and pelvic lymphadenectomy. J Urol 200I, 166:19-23.

24. Vieweg J, Whitmore WF Jr, Herr HW, Sogani PC, Russo P, Sheinfeld J, Fair WR: The role of pelvic lymphadenectomy and radical cystectomy for lymph node positive bladder cancer. The Memorial Sloan-Kettering Cancer Center experience. Cancer 1994, 73:3020-3028.

25. Konety BR, Joslyn SA, O'Donnell MA: Extent of pelvic lymphadenectomy and its impact on outcome in patients diagnosed with bladder cancer. Analysis of data from the Surveillance, Epidemiology and End Result Program database. J Urol 2003, 169:946-950.

26. Herr HW, Bochner BH, Dalbagni G, Donat SM, Reuter VE, Bajorin DF: Impact of the number of lymph nodes retrieved on outcome in patients with muscle invasive bladder cancer. J Urol 2002, I 67: 1295-1298.

27. Vazina A, Dugi D, Shariat SF, Evans J, Link R, Lerner SP: Stage specific lymph node metastasis mapping in radical cystectomy specimen. J Urol 2004, I 7 I: |830-1834.

28. Bochner BH, Cho D, Herr HW, Donat M, Kattan MW, Dalbagni G: Prospectively packaged lymph node dissections with radical cystectomy: evaluation of node count variability and node mapping. J Urol 2004, I 72: 1286-90.

29. Leissner J, Ghoneim MA, Abol-Enein H, Thuroff JW, Franzaring L Fisch M, Schulze H, Managadze G, Allhoff EP, el-Baz MA, Kastendieck $\mathrm{H}$, Buhtz P, Kropf S, Hohenfellner R, Wolf HK: Extended Radical Lymphadenectomy in patients with urothelial bladder cancer: results of a prospective multi center study. J Urol 2004, |71:139-144.
Publish with Bio Med Central and every scientist can read your work free of charge

"BioMed Central will be the most significant development for disseminating the results of biomedical research in our lifetime. "

Sir Paul Nurse, Cancer Research UK

Your research papers will be:

- available free of charge to the entire biomedical community

- peer reviewed and published immediately upon acceptance

- cited in PubMed and archived on PubMed Central

- yours - you keep the copyright

Submit your manuscript here:

http://www.biomedcentral.com/info/publishing_adv.asp
Biomedcentral 